\title{
VALIDATION AND IMPLEMENTATION OF FAILURE PARAMETERS IN INTEGRATED SIMULATIONS FOR SHORT FIBRE REINFORCED POLYPROPYLENE
}

\author{
Anna Kalteis ${ }^{a, *}$, Martin Reiter $^{a}$, Michael JerabeK $^{b}$, Zoltán MajoR $^{a}$ \\ ${ }^{a}$ Institute of Polymer Product Engineering, Johannes Kepler Universität Linz, Altenberger Straße 69, Linz, \\ Austria, 4040 \\ ${ }^{b}$ Borealis Polyolefine GmbH, St.-Peter-Straße 25, 4021 Linz \\ * corresponding author: anna.kalteis@jku.at
}

\begin{abstract}
Nowadays short fibre reinforced polymers are often used in load carrying structural parts. Compared to continuous fibre reinforced polymers they exhibit a more complex morphology. Hence the determination of the strength is a difficult but important task. Therefore this was the objective of this research.

The strength of short fibre reinforced polymers was numerically determined for low-speed to high-speed strain rates for specimens with different fibre orientations. For the failure modelling the micromechanical approach "First pseudo grain failure" in Digimat was used. The parameters for the material and failure description were determined with the reverse engineering method. Integrated finite element simulations were performed to validate the material and failure models by tensile and bending tests with different specimens. The comparison of the results of the experiments and simulations showed low deviation.
\end{abstract}

KEYWORDS: integrated simulation, short fibre reinforced polymer, failure prediction, first pseudo grain failure, reverse engineering.

\section{INTRODUCTION}

The prediction of the stiffness of a fibre reinforced material is not a difficult task anymore because there is appropriate software available. One is the software Digimat MF. There only few input parameters are needed to calculate the stiffness [1]. However the prediction of the strength of a material especially for short fibre reinforced polymers is not trivial. To perform simulations is very common nowadays, therefore in this research the strength of short glass fibre reinforced polypropylene is determined by integrated finite element simulations.

There are many different approaches how to predict the strength of a discontinuous fibre reinforced polymer. For example there is an analytical model where the strength of fibre reinforced composites can be calculated without any numerical software [2] Furthermore there are several continuum mechanics based models [3], 4], [5], [6], [7], [8], [9] and micromechanics based models [10], [11], [12], [13]. In the paper also a micromechanics based model is used namely the "First pseudo grain failure"(FPGF) model [1. A short description is given in Section 4 of this paper. The investigated material is a short glass fibre reinforced polypropylene. The glass fibre content is 32 $\mathrm{w} \%$. Because of the short fibre reinforcement the fibre distribution and orientation in the different specimens have to be investigated. The fibre orientations were determined by the computer tomographic method. The raw data from the computer tomographic measurements of the fibre orientation were provided by
FH-OÖ (Wels, Austria). Therefore a description of the CT-measurements is not given here but in [14. The experimental data were provided by Borealis Polyolefine GmbH (Linz, Austria). Standardized tensile (ISO 527) and bending tests (ISO 178) were performed with the corresponding strain rate and specimen. Specimens with different complexity of fibre distribution and orientation were used. Specimens with a uniform fibre distribution and orientation (UD multi tool) are used for the reverse engineering. For the validation specimens with a more complex fibre distribution and orientation are used. A description of the used specimens is given in Section 2

The modelling of the material behaviour is an other part of this paper. Elastic-plastic (low-speed strain rates) and elastic-viscoplastic (low-speed and highspeed strain rates) material models are generated. The needed material parameters are reverse engineered based on experimental data of tensile tests.

In Section 4 the determination of an appropriate failure criterion is described. Because the polymer is reinforced with short fibres classical failure criteria (e.g. Tsai-Hill) cannot be simply used because they are just valid for continuous fibre reinforced composites [1]. Hence as already mentioned above the "First pseudo grain failure" (FPGF) model has to be used. The failure parameters are determined with the method of reverse engineering with data of tensile tests.

The results of the material and failure modelling are validated with tensile tests with specimens with different fibre distribution and orientation as the reverse engineered ones. Further validation follows by per- 
forming bending tests. The appearing difficulties in the simulation of the bending test have to be solved and are described in Section 5.3. The validation of the material and failure model is done for low-speed and high-speed strain rates.

In this paper only the results for the low-speed strain rates are discussed.

\section{SPECIMENS}

As already mentioned different types of specimens are used for the experiments and simulations. An overview of the used specimens is given in Fig. 1 .

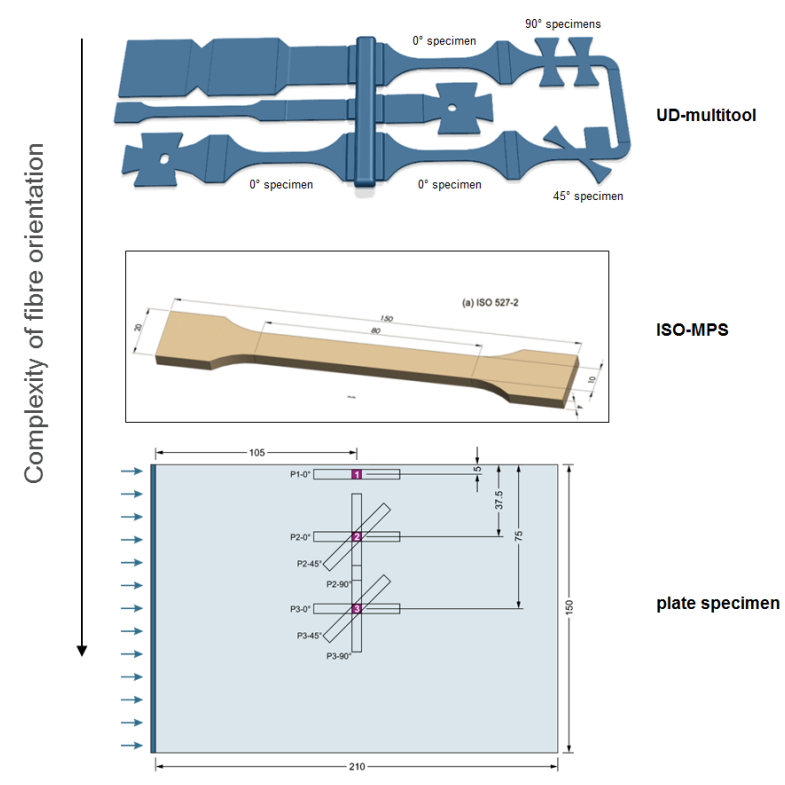

FiguRE 1. Overview of different specimens.

Different specimens are used because of their different complexity of fibre orientation. The UD-multitool was designed by Borealis Polyolefine GmbH (Linz, Austria). The specimens, which can be milled out of the tool have a highly uniform fibre distribution. The specimens $0^{\circ}, 45^{\circ}$ and $90^{\circ}$ are relevant for this paper. Because of the uniform fibre distribution these specimens are used for the reverse engineering of the material and failure parameters.

For the validation of the material and failure models the ISO-MPS specimen and the plate specimens are used. The plate specimens were milled out of a plate at different positions and under the angles $0^{\circ}, 45^{\circ}$ and $90^{\circ}$. These specimens do not show a uniform fibre orientation through the thickness as the UD-multitool specimens.

\section{Material Modelling}

For the material modelling the software Digimat MF 6.0.1 is used. For the glass fibre a linear elastic, isotropic material model is chosen. Therefore only the elastic modulus and the Poisson's ratio have to be defined. For the elastic modulus and Poisson's ratio the following values are used:
$\mathrm{E}=72000 \mathrm{MPa}, \nu=0.2$

The aspect ratio (AR) of the fibres is set to 35 [15]. An elastic-plastic (EP) and also an elastic-viscoplastic (EVP) material model are generated for the matrix. The EP and EVP material models for the matrix need more input parameters than an elastic one. The $J_{2^{-}}$ plasticity model is chosen (Eq. 1). For the hardening the exponential and linear law is used (Eq. 2). Where $R(p)$ is the hardening stress, $p$ is the accumulated plastic strain, $\mathrm{k}$ is the linear hardening modulus, $R_{\infty}$ is the hardening modulus, $m$ is the hardening exponent [1].

$$
\begin{aligned}
\sigma_{e q} & =\sqrt{J_{2}(\sigma)} \\
R(p) & =k p+R_{\infty}[1-\exp (-m p)]
\end{aligned}
$$

For the elastic-viscoplastic model some additional parameters for considering the viscoplasticity have to be determined. A law for the accumulated plastic strain rate $\dot{p}$ has to be chosen. In this paper the Current yield Norton law is chosen (Eq. 3). There the $\dot{p}$ is dependent on the initial yield stress $\sigma_{y}$, the viscoplastic stress $f$, the hardening stress $R(p)$, the viscoplastic coefficient $\eta$ and the viscoplastic exponent $m$.

$$
\dot{p}=\frac{\sigma_{y}}{\eta}\left(\frac{f}{\sigma_{y}+R(p)}\right)^{m}
$$

A detailed description is given in [1].

The above described parameters are reverse engineered with the software Digimat MX 6.0.1. With this procedure the parameters for an artificial matrix are generated. They are artificial because the real behaviour of the matrix (e.g. micro-cracking) and the influence of the fibre on the matrix (e.g. fibre-matrix debonding) are inherently considered. These influences cannot be modelled by using the parameters for the neat matrix material [16. In the reverse engineering procedure experimental stress-strain curves are needed where the microstructure (fibre orientation) is known. The parameters of the matrix are fitted to the experimental curves in an iterative optimization process [1].

The results of the material modelling for the EP and EVP material models for different strain rates are summarized in Table 1 and Table 2

\section{Failure Modelling}

The intralaminar failure criteria, which are available in Digimat are only valid for a lamina layer with unidirectional aligned fibres [1]. They can be non-interactive, interactive or failure mode based [17]. The failure criterion, which is used is Tsai-Hill 3D transversely isotropic (stress based, interactive). This failure criterion assumes that the strength in tension and compression is identical and the material is isotropic in the 2-3 plane [1]. Direction 2 and 3 are the directions transverse to the fibre orientation (direction 1 ). For the description of the failure criterion three input parameters have to be defined: 


\begin{tabular}{llll}
\hline strain rate $\left[s^{-1}\right]$ & $10^{-4}$ & $10^{-3}$ & $10^{-2}$ \\
\hline Young's modulus [MPa] & 1800 & 1800 & 1800 \\
\hline Poisson's ratio [-] & 0.42 & 0.42 & 0.42 \\
\hline Yield stress [MPa] & 4 & 4 & 4 \\
\hline Hardening modulus [MPa] & 10.3 & 13.3 & 14.2 \\
\hline Hardening exponent [-] & 154.5 & 208.2 & 188.3 \\
\hline Linear hardening modulus [MPa] & 22.6 & 19.3 & 32.2 \\
\hline
\end{tabular}

TABLE 1. Reverse engineered elastic-plastic material parameters for low-speed strain rates.

\begin{tabular}{lll}
\hline strain rate $\left[s^{-1}\right]$ & Low-speed $\left(10^{-4}, 10^{-3}, 10^{-2}\right)$ & High-speed $(0.1,1,14)$ \\
\hline Young's modulus [MPa] & 1800 & 1800 \\
\hline Poisson's ratio [-] & 0.42 & 0.42 \\
\hline Yield stress [MPa] & 3 & 4 \\
\hline Hardening modulus [MPa] & 12 & 9 \\
\hline Hardening exponent [-] & 145 & 85 \\
\hline Linear hardening modulus [MPa] & 22 & 60 \\
\hline Viscoplastic coefficient [MPa*s] & 51 & 71 \\
\hline Viscoplastic exponent [-] & 4 & 6 \\
\hline Plastic strain multiplier [-] & 1.5 & 1.9 \\
\hline
\end{tabular}

TABLE 2. Reverse engineered elastic-viscoplastic material parameters for low-speed and high-speed strain rates.

- Axial tensile strength X (tensile strength in fibre direction)

- In-plane tensile strength Y (transverse tensile strength)

- Transverse shear strength S

The failure criterion is defined as follows [1]:

$$
\begin{array}{r}
F_{A}(\sigma)=\frac{\sigma_{11}^{2}}{X^{2}}-\frac{\sigma_{11}\left(\sigma_{22}+\sigma_{33}\right)}{X^{2}}+\frac{\sigma_{22}^{2}+\sigma_{33}^{2}}{Y^{2}}+ \\
\left(\frac{1}{X^{2}}-\frac{2}{Y^{2}}\right) \sigma_{22} \sigma_{33}+\frac{\sigma_{12}^{2}+\sigma_{13}^{2}}{S^{2}}+ \\
\left(\frac{4}{Y^{2}}-\frac{1}{X^{2}}\right) \sigma_{23}^{2}
\end{array}
$$

Because a short fibre reinforced polymer with nonperfectly oriented fibres is used and not a lamina layer with perfectly aligned fibres the "First Pseudo-Grain Failure" (FPGF) method has to be used. With this method the failure criteria for laminates can also be used for composites with complex fibre orientation distributions because the short fibres are divided into regions with uniform fibre orientations [1]. This is illustrated in Fig. 2

The strength values are reverse engineered based on the EP material model. Also here the data of the tensile tests of specimens of the UD multi tool are used. In Fig. 3 the strength parameters of the failure

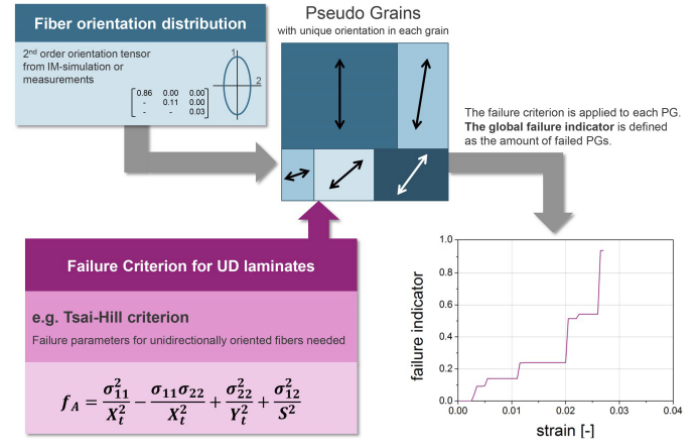

FiguRE 2. Illustration of the First Pseudo-Grain Failure method [16].

modelling for different strain rates are illustrated. It can be seen that the higher the strain rate the higher the strength is.

\section{Integrative Simulation}

\subsection{Interface Digimat CAE}

For the validation of the material model integrative Digimat-Abaqus FEM simulations are performed. For these simulations an interface is needed. Thus the software Digimat CAE 6.0.1 is used.

With this software the material properties are calculated depending on the fibre orientation either before or during the simulation. This depends on which so- 


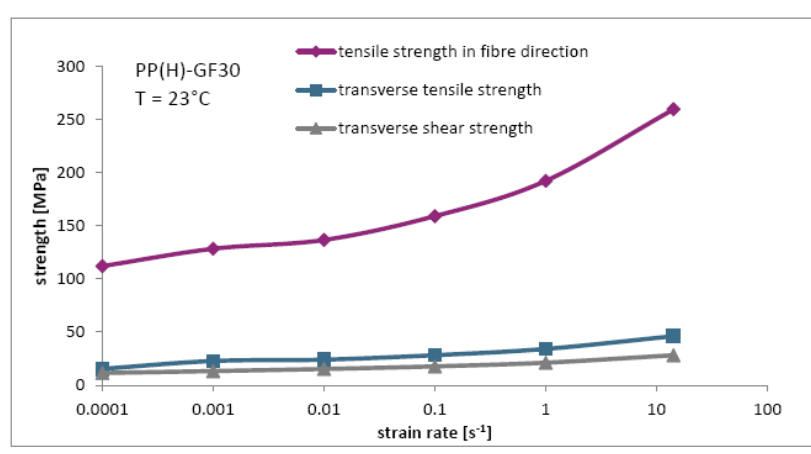

FIgURE 3. Illustration of strength parameters for different strain rates.

lution is chosen in Digimat CAE. In the following the solutions are described [1:

- Micro solution: the material properties are calculated at every iteration and not kept constant. As a result the simulation takes very long.

- Hybrid solution: the material properties are precomputed before the simulation. This enables that the simulation is sped up. With this method so called hybrid parameters are computed during the generation of the material input file.

Integrative simulations (tensile test) with the two different solution methods are performed. The results show that there is nearly no difference between micro and hybrid solution (Fig. 4). The hybrid solution is chosen for the further simulations because of the lower computation time.

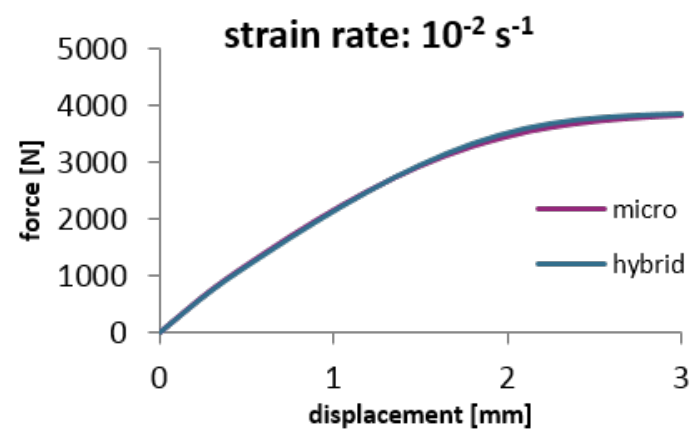

Figure 4. Comparison of hybrid and micro solution method.

\subsection{Simulation model of tensile test}

As the specimens show a fibre orientation distribution through the thickness this distribution has to be discretised for the simulation model. The discretised distribution can be modelled with a layer build-up of the specimen (Fig. 5). The layers can be modelled by partitioning the specimen through the thickness and assigning a material model with a specific fibre orientation to every partition. The number of layers can vary. The higher the number of layers the more accurate the fibre distribution is described. Furthermore the higher the number of layers is the higher the computation time because more different material models have to be assigned. For the tensile tests a 4 layer model is used. Therefore for the simulation of a tensile test a 4 layer model with the hybrid solution method is used. In this simulation model no problems occur.

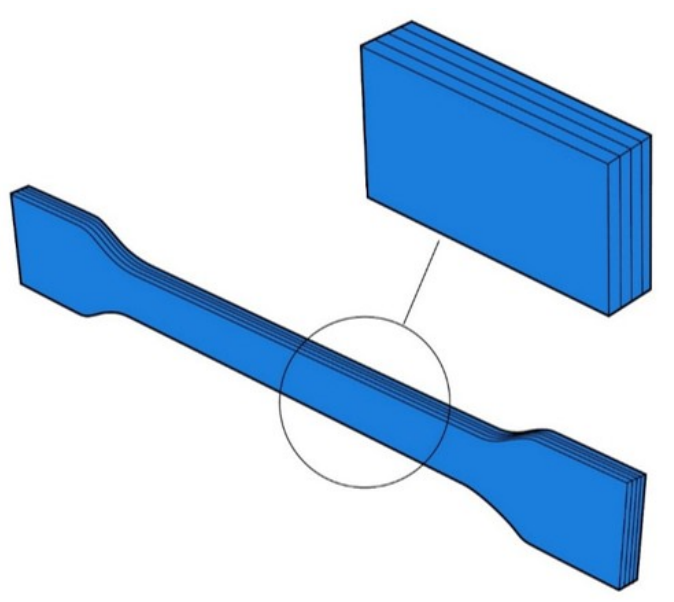

Figure 5. Simulation model with 4 layers.

\subsection{Simulation model of Bending test}

Because there are no problems in the simulation model of the tensile test these settings are also applied for the bending tests. Therefore a bending test with a 4 layer model and with the hybrid solution method is modelled. In contrast to the tensile test simulation model, the bending simulation model shows various complications by using exactly the same simulation approach. Therefore the settings of the simulation model of a tensile test cannot be directly transferred to the simulation model of the bending test. The simulation model of the bending test has to be modified. The problems in the simulation model of the bending test (hybrid solution, 4 layers) and the belonging solutions are explained in Table 3

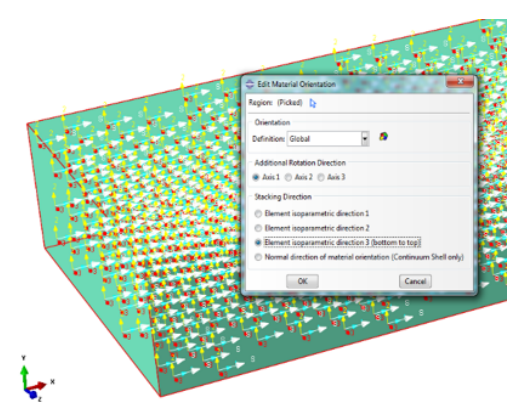

FiguRE 6. Specimen with global fibre orientation.

The soft contact, which is used is a normal behaviour with exponential law between the master and slave surface. This contact is implemented in Abaqus. Two parameters (clearance and pressure) have to be defined. With this contact the pressure of the stamp 


\begin{tabular}{|c|c|c|}
\hline & Problem & Solution \\
\hline 1 & $\begin{array}{l}\text { Fibre orientation does not rotate with spec- } \\
\text { imen }\end{array}$ & Applying global fibre orientation (Fig. 6) \\
\hline 2 & Elements break under pressure & $\begin{array}{l}\text { Soft contact between specimen and stamp } \\
\text { (Fig. 7) }\end{array}$ \\
\hline 3 & "Kink" in curve (Fig. 8) & 10 layer model instead of 4 layer model \\
\hline 4 & $\begin{array}{l}\text { Considering of different behaviour under } \\
\text { compression [18] }\end{array}$ & $\begin{array}{l}\text { Adjustment of hardening modulus for the } \\
\text { upper } 5 \text { layers (Fig. } 9 \text { ) }\end{array}$ \\
\hline 5 & $\begin{array}{l}\text { No valid hybrid parameters could be deter- } \\
\text { mined for some layers }\end{array}$ & Using micro solution \\
\hline 6 & Specimen breaks at a too low stress & Adjustment of failure parameters \\
\hline
\end{tabular}

TABLE 3. Description of the problem and the corresponding solution for the bending simulation model.

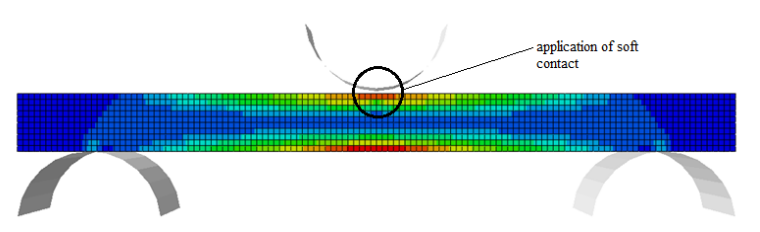

FiguRE 7. Illustration of position of applied soft contact.

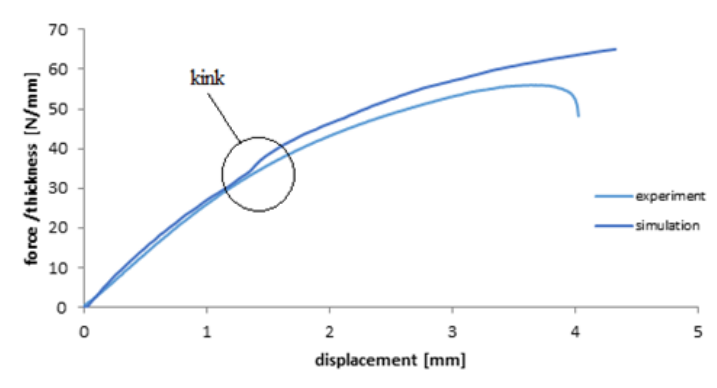

FiguRE 8. Illustration of kink in curve.

a)

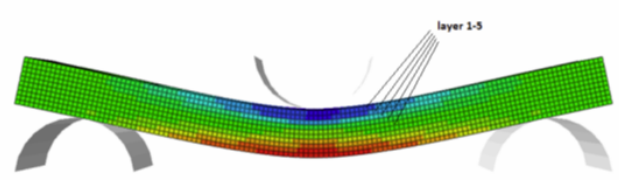

b)

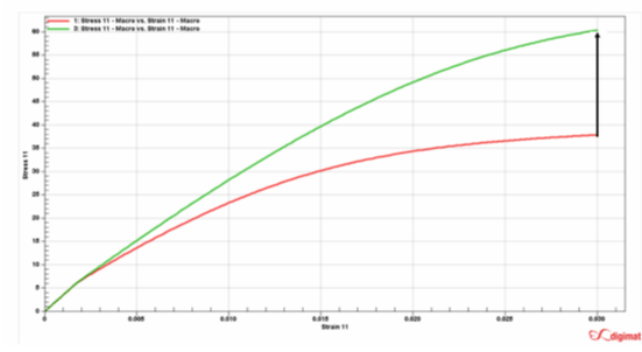

Figure 9. Adjustment of material behaviour under compression; a) illustration of layers for the adjustment; b) red curve: stress-strain curve without adjustment, green curve: stress-strain curve with adjustment. is distributed over a larger area of the specimen [19. Therefore the stress concentrations on the specimen are lowered and as a result the specimen does not break under pressure anymore.

The parameters are investigated by performing simulations of a bending test to find the most appropriate ones to solve the problem that the elements break under pressure.

The reason for using a 10 layer model for the bending test is that the stress differences in the 10 layer model are lower than in a 4 layer model. This is because in the 10 layer model there is a smoother transition between the different fibre orientations. Therefore the "kink" in the curve vanishes.

Unlike in the simulation model of the tensile test in the simulation model of the bending test the hybrid solution cannot be used. The reason for this is that in some layers no valid hybrid parameters could be determined by the software. Therefore the micro solution has to be chosen.

The failure parameters are reverse engineered for the EP material model. But for the bending tests the EVP material model is used in order to consider the strain rate dependency. Therefore the reverse engineered failure parameters may not fit as well for the EVP material model as for the EP material model. As a result the parameters are fitted as it is described in Section 6.2.

\section{Results}

\subsection{Results of tensile test}

Fig. 10 shows the result of the tensile test for a lowspeed strain rate. The material model is the elasticplastic one with strain rate of $10^{-3} \mathrm{~s}^{-1}$. As the strain rate for the simulation is implemented in the elasticplastic material model also for the low-speed strain rates the dynamic explicit solver can be used to speed up the simulation. Also an uncoupled simulation was performed in Digimat MF. A difference in the failure stress between the simulations performed in Abaqus 6.14 (integrative simulation) and Digimat MF can be seen. 


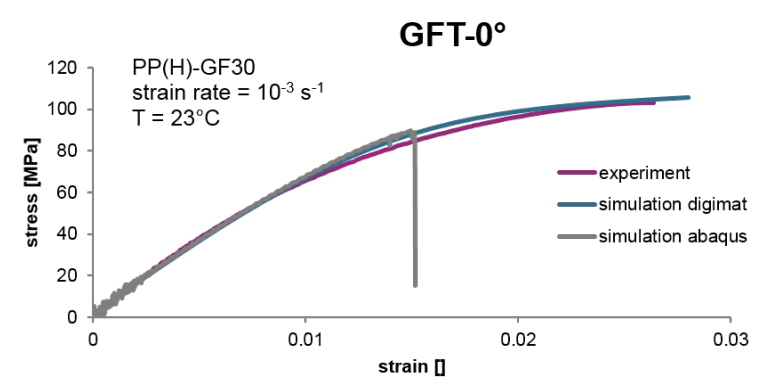

FiguRE 10. Comparison of stress-strain curves of experiment, simulation performed in Digimat MF 6.0.1 and simulation performed in Abaqus 6.14.

The reason for this is that the specimen shows a stress concentration in the region of the shoulder (Fig. 11).

a)

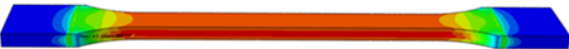

b)

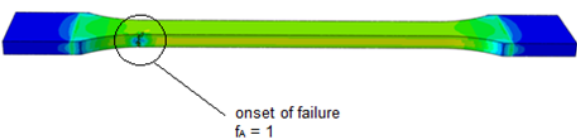

FiguRE 11. Illustration of location of stress concentrations; a) specimen before failure, b) failed specimen.

The notch effect at the specimen typically does not appear in reality. In reality the ISO-MPS specimen should break in the middle. In the simulation this cannot be realized in any specimen. Because the simulation model itself cannot be modified to consider the notch effect, the failure parameters have to be fitted. Therefore the parameters are fitted in this way that the notch effect can be considered. This fitting is performed by lowering the strain rate dependency by a power of 10 . This means that the failure parameters for the strain rate of $10^{-2} \mathrm{~s}^{-1}$ are used for the elasticplastic material model for the strain rate of $10^{-3} \mathrm{~s}^{-1}$. In the following figure the results of the experiment and the simulation with the fitted failure parameters are shown.

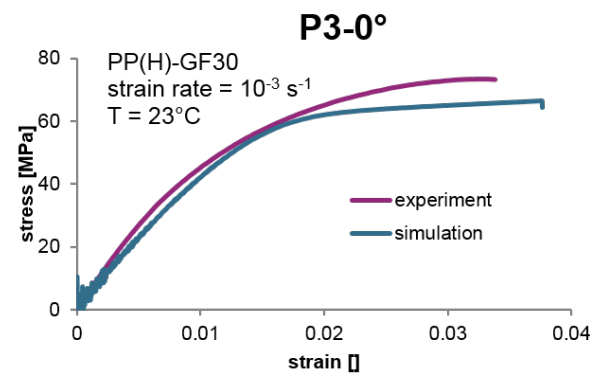

Figure 12. Comparison of stress-strain curves of experiment and simulation performed in Abaqus 6.14 with fitted failure parameters.

\subsection{Results of Bending test}

The bending test simulations are performed with the elastic-viscoplastic low-speed material model. Because of the viscoplastic behaviour the strain rate has to be defined in Abaqus. The static solver is used.

In the following the result of the bending test for a specimen with misaligned fibres with the not fitted failure parameters is shown (Fig. 13). As it can be seen the specimen breaks at a lower force than the experiment. One reason for this is described in Section 5.3 .

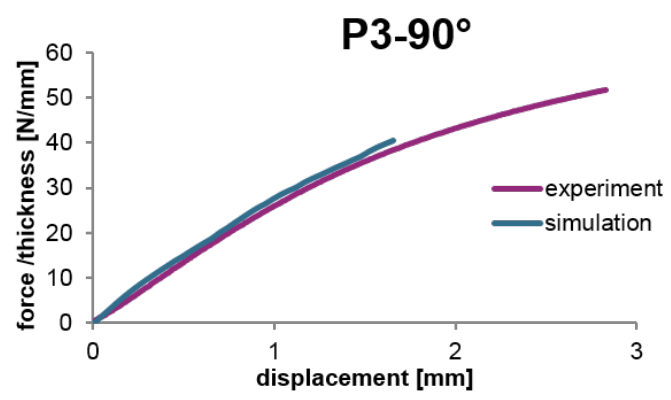

Figure 13. Comparison of force/thicknessdisplacement curves of experiment and simulation.

Therefore the in-plane tensile and the transverse shear failure parameters are fitted. The axial tensile strength is kept constant because it has the most influence on layers with fibres, which are nearly perfectly aligned. In Table 4 the previous and the fitted parameters are listed for the two different parameters. The difference between the previous and the fitted value is not very big. Nevertheless these little increased values have a huge influence on the global result, which is illustrated in Fig. 14

\begin{tabular}{lll}
\hline Strength parameter & Previous value & Fitted value \\
\hline $\begin{array}{l}\text { In-plane tensile } \\
\text { strength }\end{array}$ & $22.83 \mathrm{MPa}$ & $25.32 \mathrm{MPa}$ \\
\hline $\begin{array}{l}\text { Transverse } \\
\text { shear strength }\end{array}$ & $13.38 \mathrm{MPa}$ & $13.60 \mathrm{MPa}$ \\
\hline
\end{tabular}

TABLE 4. Previous and fitted strength parameters.

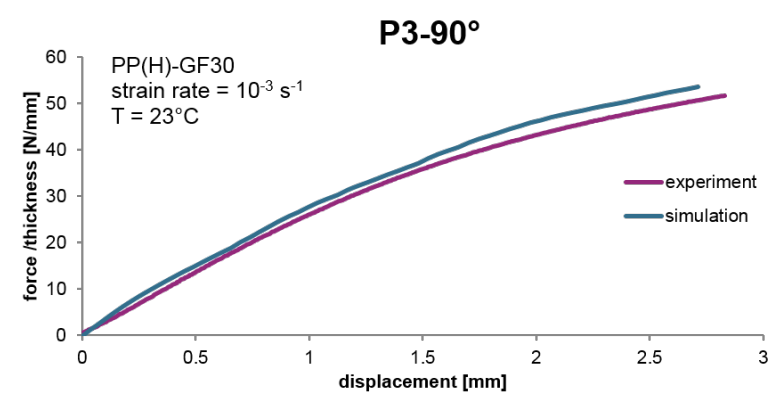

Figure 14. Comparison of force/thicknessdisplacement curves of experiment and simulation with fitted strength parameters. 


\section{Conclusion}

With the knowledge of the specimen's fibre orientation simulations can be set up, where this fibre orientation is considered. Material and failure modelling was done for specimens with different fibre orientations and for low-speed to high-speed strain rates. It was shown that it is possible to determine failure in tensile and bending tests with low deviation (Fig 15).

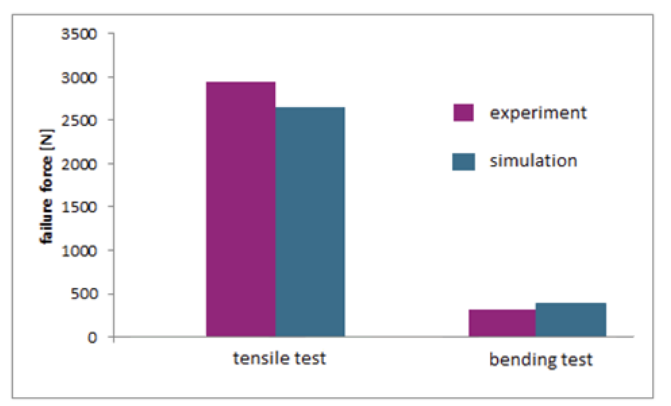

Figure 15. Illustration of the deviation between failure force in the experiment and in the simulation.

Many influences have to be considered in a bending test (e.g. applying a global fibre orientation). Little different values of failure strength parameters have a huge influence on the failure strength of the specimen.

\section{ACKNOWLEDGEMENTS}

I would like to thank Dr. Michael Jerabek for the possibility to do this research in cooperation with Borealis Polyolefine GmbH.

\section{REFERENCES}

[1] Digimat documentation 6.0.1. 2015.

[2] S.-Y. Fu, B. Lauke, Y.-W. Mai. Science and engineering of short fibre reinforced polymer composites. Woodhead Publishing, 2009.

[3] J. Fritsch. Charakterisierung und Modellierung glasfaserverstärkter Thermoplaste unter dynamischen Lasten. Fraunhofer EMI, 2012.

[4] A. Koukal. Crash- und Bruchverhalten von Kunststoffen im Fußgängerschutz von Fahrzeugen. Ph.D. thesis, Technische Universität München. 2014.

[5] J. Schöpfer. Spritzgussbauteile aus kurzfaserverstärkten Kunststoffen: Methoden der Charakterisierung und Modellierung zur nichtlinearen Simulation von statischen und crashrelevanten Lastfällen. Ph.D. thesis, Institut für Verbundwerkstoffe GmbH, Kaiserslautern. 2012.

[6] M. Nutini, M. Vitali. Simulation anisotropy with ls-dyna in glass-reinforced, polypropylene-based components. Material IV-Faserverstärkte Kunststoffe 2010 .
[7] M. Vogler. New material modeling approaches for thermoplastics, composites and organic sheet. 9th European LS-Dyna Conference 2013.

[8] A. Launay, M. Maitournam, Y. Marco, I. Raoult. Multiaxial fatigue models for short glass fibre reinforced polyamide. Part I: Nonlinear anisotropic constitutive behaviour for the cyclic response. International Journal of Fatigue 2012.

[9] A. Launay, M. Maitournam, Y. Marco, I. Raoult. Multiaxial fatigue models for short glass fiber reinforced polyamide. Part II: Fatigue life estimation. International Journal of Fatigue 2012.

[10] P. Gumbsch, et. al. Entwicklung einer Methode zur Crashsimulation von langfaserverstärkten Thermoplast (LFT) Bauteilen auf Basis der Faserorientierung aus der Formfüllsimulation. FAT-Schriftenreihe 2842016.

[11] M. Kaiser. Beitrag zur mikromechanischen Berechnung kurzfaserverstärkter

Kunststoffe-Deformation und Versagen. Ph.D. thesis, Naturwissenschaftlich-Technische Fakultät III Chemie, Pharmazie, Bio- und Werkstoffwissenschaften, Saarbrücken. 2013.

[12] A. Krairi, I. Doghri, G. Robert. Multiscale high cycle fatigue models for neat and short fiber reinforced thermoplastic polymers. International Journal of Fatigue 2016.

[13] W. Lutz, M. Dong, K. Zhu, S. Schmauder. Modeling of damage in fibre and particle reinforced composites, in Damage and its evolution in fiber-composite materials: simulation and non-destructive testing. ISD-Verlag, 2006.

[14] J. Kastner, E. Schlotthauer, D. Angermaier, G. Zitzenbacher. Quantitative Messung von Faserlängen und -verteilung in faserverstärkten Kunststoffteilen mittels $\mu$-Röntgen-Computertomographie. DGZfP-Jahrestagung 2007.

[15] R. Teschner. Glasfasern. Springer Vieweg, 2013.

[16] M. Reiter. Development, implementation and validation of an integrated simulation methodology for discontinuous fiber reinforced composites. Ph.D. thesis, Institute of Polymer Product Engineering, Johannes Kepler University, Linz. 2014.

[17] I. M. Daniel, O. Ishai. Engineering mechanics of composite materials. Oxford University Press 2006.

[18] A. Hartl. Mechanical Behavior of Short Glass Fiber Reinforced and Particle Modified Polypropylene, Influence of Material Anisotropy and Loading Mode. Ph.D. thesis, Institute of Polymeric Materials Testing, Johannes Kepler University, Linz. 2014.

[19] Abaqus analysis user's guide, 6.14. 2014. 